\title{
What is the proper ventilation strategy during laparoscopic surgery?
}

\author{
Youn Yi Jo and Hyun-Jeong Kwak \\ Department of Anesthesiology and Pain Medicine, Gachon University Gil Medical Center, Incheon, Korea
}

The main stream of intraabdominal surgery has changed from laparotomy to laparoscopy, but anesthetic care for laparoscopic surgery is challenging for clinicians, because pneumoperitoneum might aggravate respiratory mechanics and arterial oxygenation. The authors reviewed the literature regarding ventilation strategies that reduce deleterious pulmonary physiologic changes during pneumoperitoneum for laparoscopic surgery under general anesthesia and make appropriate recommendations.

Key Words: Pneumoperitoneum, Respiratory, Ventilator strategy.

\section{Introduction}

As the previous standard laparotomic procedure now alternates with laparoscopy, anesthetic attentions should be reestablished for laparoscopic procedures. Although laparoscopy has the merits of early recovery, less pain, and short hospital stay, pneumoperitoneum for suitable surgical visualization and instrument manipulation, produces negative physiologic changes and modifies respiratory mechanics [1].

Carbon dioxide $\left(\mathrm{CO}_{2}\right)$ pneumoperitoneum increases intraabdominal pressure, and thus, may alter respiratory mechanics, by decreasing lung volume and increasing airway pressure and end-tidal $\mathrm{CO}_{2}$ tension. During pneumoperitoneum, peak and

Corresponding author: Hyun-Jeong Kwak, M.D.

Department of Anesthesiology and Pain Medicine, Gachon University, Gil Medical Center, 21, Namdong-daero 774beon-gil, Namdong-gu, Incheon 21565, Korea

Tel: 82-32-460-3637, Fax: 82-32-469-6319

Email: hyun615@gilhospital.com

ORCID: https://orcid.org/0000-0003-4432-8510

Received: July 6, 2017.

Revised: July 14, 2017 (1st); July 14, 2017 (2nd).

Accepted: July 14, 2017.

Korean J Anesthesiol 2017 December 70(6): 596-600 https://doi.org/10.4097/kjae.2017.70.6.596 plateau airway pressures increase by more than $50 \%$ and lead to around 50\% decreases in dynamic and static lung compliances in the Trendelenburg position [2]. Furthermore, in this position, diminished respiratory compliance might not recover completely even after $\mathrm{CO}_{2}$ deflation [3]. In an earlier study, pulmonary compliance decreased by up to $50 \%$ at an intra-abdominal pressure of $16 \mathrm{mmHg}$ in a head-up tilt position during laparoscopic cholecystectomy [4].

Regarding gas exchanges, a previous clinical study revealed that alveolar dead space-to-tidal volume ratio was significantly greater during laparoscopic than open surgery [5]. Consequent diaphragm cephalic shift induces basal lung collapse, reducing functional residual capacity and increasing intrapulmonary shunt and ventilation-perfusion mismatch. These changes might also cause hypoxemia or increase the alveolar-arterial oxygen tension gradient $\left(\mathrm{AaDO}_{2}\right)$ [6]. Here, we propose appropriate ventilator strategies to reduce deleterious pulmonary physiologic changes during laparoscopic surgery under general anesthesia.

\section{Volume- vs. Pressure-controlled Ventilation}

Volume-controlled ventilation (VCV) has been widely used for general anesthesia, and has the merit of a guaranteed preset tidal volume. However, it presents the risk of increased airway pressure when pulmonary compliances change. Unlike VCV, pressurecontrolled ventilation (PCV) has less risk of barotrauma because

(c) This is an open-access article distributed under the terms of the Creative Commons Attribution Non-Commercial License (http://creativecommons.org/ licenses/by-nc/4.0/), which permits unrestricted non-commercial use, distribution, and reproduction in any medium, provided the original work is properly cited. 
peak airway pressure is limited, but it cannot ensure tidal volume.

During pneumoperitoneum, PCV might be advocated because of a significant increase in airway pressure after $\mathrm{CO}_{2}$ insufflation. A previous randomized trial showed that PCV provides lower peak airway pressures and greater dynamic lung compliances at 60 and $120 \mathrm{~min}$ during robot-assisted laparoscopic radical prostatectomy in the steep Trendelenburg position than VCV at similar tidal volumes [7]. Other reports have also demonstrated significantly higher compliance with lower peak airway pressure for PCV than VCV during gynecologic laparoscopy $[8,9]$. In a study of urologic laparoscopy, dynamic lung compliance improved after switching to PCV at the end of a VCV sequence when tidal volume, respiratory rate, and $\mathrm{FiO}_{2}$ were maintained at constant levels [10]. However, despite positive results for respiratory compliance, PCV might not improve arterial oxygenation. The majority of clinical studies on the topic have suggested $\mathrm{PaO}_{2}$ levels are similar for PCV and VCV [7-10], and that $\mathrm{PaO}_{2} / \mathrm{FiO}_{2}$ ratios were comparable after adapting PCV or VCV (446 \pm 77 vs. $458 \pm 64)$ [10]. In a prospective comparative gynecologic laparoscopy study, similar $\mathrm{PaO}_{2}$ values were reported for VCV and PCV from anesthesia induction to extubation [9].

Even in the steep Trendelenburg position, PCV might not improve oxygenation despite improving dynamic lung compliance. Choi et al. [7] reported that $\mathrm{PaO}_{2}$ significantly decreased after pneumoperitoneum during both PCV and VCV and there was no difference in $\mathrm{PaO}_{2}$, despite PCV had significantly higher dynamic compliance than VCV after 60 or $120 \mathrm{~min}$ in the steep Trendelenburg position with pneumoperitoneum. However, in obese patients (body mass index [BMI] $>35 \mathrm{~kg} / \mathrm{m}^{2}$ ), PCV might help improve oxygenation during pneumoperitoneum [11]. In a previous clinical study, it was observed that PCV produced significantly higher $\mathrm{PaO}_{2}$ than VCV during laparoscopic bariatric surgery [11], and the authors suggested that improved ventilation/perfusion ratio as evidenced by a marked difference in $\mathrm{AaDO}_{2}$, might be responsible for oxygenation differences in these two ventilator modes [11]. It was concluded that greater inspiratory flow for PCV than VCV (52 vs. $41 \mathrm{~L} / \mathrm{min}$ ) at a given tidal volume might better allow alveolar recruitment [11]. These findings suggest PCV might have more beneficial effects on the respiratory mechanics and arterial oxygenation than VCV in the morbidly obese during laparoscopy.

\section{Positive End-expiratory Pressure (PEEP)}

Many clinicians express concern about hemodynamic deterioration when positive end-expiratory pressure (PEEP) is added at an elevated intra-abdominal pressure. Theoretically, pneumoperitoneum increases intra-abdominal pressure, and consequently intra-thoracic pressure, which might inhibit venous return and reduce cardiac output, and the application of PEEP might aggravate these responses. A previous animal study of laparoscopic pelvic lymphadenectomy showed that pneumoperitoneum at $15 \mathrm{mmHg}$ had no negative cardiovascular effect, but adding $8 \mathrm{cmH}_{2} \mathrm{O}$ of PEEP markedly aggravated hemodynamic parameters [12]. In addition, in another animal model, the application of 5 or $10 \mathrm{cmH}_{2} \mathrm{O}$ of PEEP during pneumoperitoneum significantly perturbed hemodynamic variables. The authors suggested that pneumoperitoneum might increase ventricular afterload, and thus, aggravate the adverse effects of PEEP, especially in critically ill patients [13].

Optimal PEEP might improve arterial oxygenation without inducing hemodynamic deterioration during pneumoperitoneum. In a comparative study of the PEEP application at 5 $\mathrm{cmH}_{2} \mathrm{O}$ vs. no PEEP during endoscopic robot-assisted radical prostatectomy in the steep Trendelenburg position, PEEP significantly increased $\mathrm{PaO}_{2}$ from $3 \mathrm{~h}$ after pneumoperitoneum as compared with no PEEP, but no intergroup differences were observed between mean arterial pressures, heart rates, or central venous pressures during pneumoperitoneum [14]. In a study undertaken to determine optimal PEEP level during laparoscopic urologic surgery, $\mathrm{PaO}_{2}$ and $\mathrm{AaDO}_{2}$ were found to be higher in patients with any level of $\operatorname{PEEP}\left(3,5,7\right.$, or $\left.10 \mathrm{cmH}_{2} \mathrm{O}\right)$ than in those without [15]. It was suggested that PEEP at $7 \mathrm{cmH}_{2} \mathrm{O}$ might be optimal for improving $\mathrm{PaO}_{2}$ without excessively increasing peak airway pressure or aggravating hemodynamic parameters [15]. During laparoscopic cholecystectomy, levels of PEEP from 5 to $20 \mathrm{cmH}_{2} \mathrm{O}$ did not reduce abdominal perfusion pressure, which was calculated by subtracting intra-abdominal pressure during pneumoperitoneum at $15 \mathrm{mmHg}$ from mean arterial pressure [16]. Another study also reported that PEEP at $10 \mathrm{cmH}_{2} \mathrm{O}$ increased lung compliance and arterial oxygenation without hemodynamic compromise during laparoscopic cholecystectomy [17].

In the morbidly obese during laparoscopic gastric banding surgery, PEEP of $10 \mathrm{cmH}_{2} \mathrm{O}$ alone did not improve $\mathrm{PaO}_{2}$ in the supine position, but a combination of PEEP and the head-up position improved oxygenation versus no PEEP in the supine position [18]. Erlandsson et al. [19] suggested based on electric impedance tomographic findings, the optimal level of PEEP was $15 \pm 1 \mathrm{cmH}_{2} \mathrm{O}$ in morbidly obese patients with stable cardiac index during laparoscopic procedures. Taken together, it appears that the application of an optimal level of PEEP might improve arterial oxygenation adversely affecting hemodynamic parameters.

\section{Alveolar Recruitment Maneuver}

The alveolar recruitment maneuver is used to improve arterial oxygenation in cases of lung injury [20,21]. It opens collapsed 
alveoli while PEEP prevents alveolar de-recruitment under low tidal volume ventilation $[22,23]$.

During laparoscopic gynecologic surgery, pre-emptive application of alveolar recruitment (10 manual breaths at peak inspiratory pressure of $40 \mathrm{cmH}_{2} \mathrm{O}$ with PEEP at $15 \mathrm{cmH}_{2} \mathrm{O}$ ) before peritoneal gas insufflation significantly improved $\mathrm{PaO}_{2}$ and alveolar-to-arterial oxygen tension gradient at 15 and $30 \mathrm{~min}$ after gas insufflation as compared with no recruitment maneuver during constant $\mathrm{FiO}_{2}$ of 0.35 and tidal volume of $10 \mathrm{ml} / \mathrm{kg}$ without PEEP [24]. In a comparative study of obese patients (BMI $>35 \mathrm{~kg} / \mathrm{m}^{2}$ ) and normal weight patients $\left(\mathrm{BMI}<25 \mathrm{~kg} / \mathrm{m}^{2}\right)$ in the $30^{\circ}$ head-up position, the recruitment maneuver combined with PEEP at $10 \mathrm{cmH}_{2} \mathrm{O}$ improved end-expiratory lung volume, respiratory mechanics, and arterial oxygenation, whereas PEEP alone caused no improvement in obese or normal weight patients [25]. Another study compared the effects of only PEEP $\left(10 \mathrm{cmH}_{2} \mathrm{O}\right.$ ), only recruitment maneuver (inspiratory hold at 55 $\mathrm{cmH}_{2} \mathrm{O}$ for $10 \mathrm{~s}$ ), and recruitment maneuver followed by PEEP in the morbidly obese $\left(\mathrm{BMI}>40 \mathrm{~kg} / \mathrm{m}^{2}\right)$ and showed that the recruitment maneuver and PEEP in combination significantly reduced atelectasis and increased $\mathrm{PaO}_{2} / \mathrm{FiO}_{2}$ ratio versus baseline, but PEEP or the recruitment maneuver alone did not improve these parameters [26].

Although the recruitment maneuver improves oxygenation deficits, its effect might not be persistent after surgery [27,28]. In a robot-assisted laparoscopic prostatectomy study, a single recruitment maneuver of $40 \mathrm{cmH}_{2} \mathrm{O}$ for 40 seconds at constant PEEP of $15 \mathrm{cmH}_{2} \mathrm{O}$ in the Trendelenburg position improved $\mathrm{PaO}_{2}$ during pneumoperitoneum, but their effects were shortlived after desufflation [27]. Also, in morbidly obese patients, the recruitment maneuver (4 sustained lung inflations at peak inspiratory pressure of $50 \mathrm{cmH}_{2} \mathrm{O}$ with PEEP at $12 \mathrm{cmH}_{2} \mathrm{O}$ ) significantly increased intraoperative $\mathrm{PaO}_{2}$ and dynamic compliance versus PEEP at $4 \mathrm{cmH}_{2} \mathrm{O}$ alone, but its beneficial effects disappeared rapidly after tracheal extubation [28]. Furthermore, application of the recruitment maneuver increased vasopressor requirements due to hemodynamic deterioration [28].

In summary, the recruitment maneuver with optimal PEEP might be beneficial for improving arterial oxygenation during mechanical ventilation, but cautious hemodynamic monitoring is required.

\section{Changes in Inspiratory to Expiratory Time Ratio}

Inverse ratio ventilation means extending the inspiratory time beyond that required to maintain a conventional inspiratory to expiratory $(\mathrm{I}: \mathrm{E})$ ratio of $1: 2$. Prolonged $\mathrm{I}: \mathrm{E}$ ratio ventilation has the possible merit of improving oxygen delivery by preventing an alveolar collapse in acute lung injury or acute respiratory distress syndrome. However, excessive prolongation of inspiratory time poses the risk of reduced cardiac output, especially in patients with poor pulmonary compliance [29-32]. In addition, theoretically, a prolonged inspiratory time might result in $\mathrm{CO}_{2}$ retention due to a reduced expiratory time.

The effects of prolonged inspiratory time on respiratory mechanics and oxygenation remain controversial during general anesthesia [33-37]. The application of equal I : E ratio (1:1) ventilation for $20 \mathrm{~min}$ did not improve respiratory mechanics or arterial oxygen saturation during laparoscopic surgery as compared with conventional ratio ventilation $(1: 2)$ [33]. However, in an analysis of seven trials, including one-lung ventilation or pneumoperitoneum, equal ratio ventilation significantly improved oxygenation at $60 \mathrm{~min}$ after intervention, but not at 20 or $30 \mathrm{~min}$ after intervention [34]. In the same study, during laparoscopic surgery, equal ratio ventilation improved oxygenation throughout intervention [34]. In a comparative study, the $\mathrm{PaO}_{2} /$ $\mathrm{FiO}_{2}$ ratio was significantly higher at $\mathrm{I}: \mathrm{E}$ ratios of $1: 1,2: 1$, and $1: 2$ with $\mathrm{PEEP}$ at $5 \mathrm{cmH}_{2} \mathrm{O}$ than at an $\mathrm{I}: \mathrm{E}$ ratio of $1: 2$ without $\mathrm{PEEP}$ at $60 \mathrm{~min}$ after pneumoperitoneum for gynecologic laparoscopy [35], and $\mathrm{PaCO}_{2}$ was significantly lower at an I : E ratio of $2: 1$ than at other ratios at $60 \mathrm{~min}$ after pneumoperitoneum [35]. The authors that suggested prolonged I : E ratio ventilation provided superior arterial oxygenation and $\mathrm{CO}_{2}$ elimination without compromising lung mechanics as compared with conventional ratio ventilation with PEEP in patients undergoing laparoscopic surgery [35]. A recent clinical study on laparoscopic bariatric surgery demonstrated that sequentially changes in $\mathrm{I}$ : E ratio from $1: 2$ to $1: 1$ to $2: 1$ while applying PEEP at $5 \mathrm{cmH}_{2} \mathrm{O}$, significantly reduced peak airway pressure and increased mean airway pressure and dynamic compliance without hemodynamic consequences [36]. Also, $\mathrm{PaO}_{2}$ was significantly higher and $\mathrm{AaDO}_{2}$ was significantly lower at an $\mathrm{I}: \mathrm{E}$ ratio of $2: 1$ than at the conventional ratio of $1: 2$ [36]. During this previous clinical study, $\mathrm{PaCO}_{2}$ levels were similar regardless of $\mathrm{I}: \mathrm{E}$ ratio differences [36]. Taken together, increased I : E ratio (1: 1 or 2 : 1) ventilation might improve respiratory mechanics and arterial gas exchanges, including arterial oxygenation and $\mathrm{CO}_{2}$ elimination, by reducing dead space and increasing alveolar ventilation during pneumoperitoneum $[31,32,35,36]$.

\section{Deep Neuromuscular Block and Respiratory Benefits}

The benefits of deep neuromuscular blocks for laparoscopic procedures are controversial and most of the studies undertaken have only sought to improve surgical conditions [38-40]. Theoretically, deep neuromuscular block permits a lower abdominal insufflation pressure, which leads to better respiratory mechanics and gas exchange. In one clinical study, it was noted that the average adjusted intra-abdominal pressure was significantly low- 
er after deep neuromuscular block as compared with moderate block (9.3 vs. $12 \mathrm{mmHg}$ ) [38]. However, another study demonstrated no benefit in terms of reducing insufflation pressure [39]. To the best of our knowledge, no published clinical evidence demonstrates that deep neuromuscular block has a beneficial effect on respiratory mechanics during pneumoperitoneum. However, one case report described a successful anesthetic experience with a deep neuromuscular block for a laparoscopic appendectomy in a patient with end-stage lung disease [41].

\section{Conclusion}

In conclusion, PCV rather than VCV, the application of PEEP and the recruitment maneuver, and prolonged I : E ratio ventilation might improve respiratory mechanics or oxygenation during laparoscopic surgery, but if employed, hemodynamic compromise should be considered.

\section{ORCID}

Hyun Jeong Kwak, https://orcid.org/0000-0003-4432-8510

Youn Yi Jo, https://orcid.org/0000-0002-9214-7039

\section{References}

1. Sharma KC, Brandstetter RD, Brensilver JM, Jung LD. Cardiopulmonary physiology and pathophysiology as a consequence of laparoscopic surgery. Chest 1996; 110: 810-5.

2. Jo YY, Kim JY, Chang YJ, Lee S, Kwak HJ. The effect of equal ratio ventilation on oxygenation, respiratory mechanics, and cerebral perfusion pressure during laparoscopy in the trendelenburg position. Surg Laparosc Endosc Percutan Tech 2016; 26: 221-5.

3. Oikkonen M, Tallgren M. Changes in respiratory compliance at laparoscopy: measurements using side stream spirometry. Can J Anaesth 1995; 42: 495-7.

4. Obeid F, Saba A, Fath J, Guslits B, Chung R, Sorensen V, et al. Increases in intra-abdominal pressure affect pulmonary compliance. Arch Surg 1995; 130: 544-7.

5. Nguyen NT, Anderson JT, Budd M, Fleming NW, Ho HS, Jahr J, et al. Effects of pneumoperitoneum on intraoperative pulmonary mechanics and gas exchange during laparoscopic gastric bypass. Surg Endosc 2004; 18: 64-71.

6. Srivastava A, Niranjan A. Secrets of safe laparoscopic surgery: anaesthetic and surgical considerations. J Minim Access Surg 2010; 6: 91-4.

7. Choi EM, Na S, Choi SH, An J, Rha KH, Oh YJ. Comparison of volume-controlled and pressure-controlled ventilation in steep Trendelenburg position for robot-assisted laparoscopic radical prostatectomy. J Clin Anesth 2011; 23: 183-8.

8. Oğurlu M, Küçük M, Bilgin F, Sizlan A, Yanarateş O, Eksert S, et al. Pressure-controlled vs volume-controlled ventilation during laparoscopic gynecologic surgery. J Minim Invasive Gynecol 2010; 17: 295-300.

9. Lian M, Zhao X, Wang H, Chen L, Li S. Respiratory dynamics and dead space to tidal volume ratio of volume-controlled versus pressurecontrolled ventilation during prolonged gynecological laparoscopic surgery. Surg Endosc 2016 [Epub ahead of print].

10. Balick-Weber CC, Nicolas P, Hedreville-Montout M, Blanchet P, Stéphan F. Respiratory and haemodynamic effects of volume-controlled vs pressure-controlled ventilation during laparoscopy: a cross-over study with echocardiographic assessment. Br J Anaesth 2007; 99: 429-35.

11. Cadi P, Guenoun T, Journois D, Chevallier JM, Diehl JL, Safran D. Pressure-controlled ventilation improves oxygenation during laparoscopic obesity surgery compared with volume-controlled ventilation. Br J Anaesth 2008; 100: 709-16.

12. Luz CM, Polarz H, Böhrer H, Hundt G, Dörsam J, Martin E. Hemodynamic and respiratory effects of pneumoperitoneum and PEEP during laparoscopic pelvic lymphadenectomy in dogs. Surg Endosc 1994; 8: 25-7.

13. Moffa SM, Quinn JV, Slotman GJ. Hemodynamic effects of carbon dioxide pneumoperitoneum during mechanical ventilation and positive end-expiratory pressure. J Trauma 1993; 35: 613-7.

14. Meininger D, Byhahn C, Mierdl S, Westphal K, Zwissler B. Positive end-expiratory pressure improves arterial oxygenation during prolonged pneumoperitoneum. Acta Anaesthesiol Scand 2005; 49: 778-83.

15. Lee HJ, Kim KS, Jeong JS, Shim JC, Cho ES. Optimal positive end-expiratory pressure during robot-assisted laparoscopic radical prostatectomy. Korean J Anesthesiol 2013; 65: 244-50.

16. Lim CH, Koh Y, Lee HW, Khil JY, Suh SO, Kim YC, et al. Effect of positive end expiratory pressure on intra-abdominal pressure and abdominal perfusion pressure at an increased intra-abdominal pressure. Korean J Anesthesiol 2007; 53: S31-5.

17. Sen O, Erdogan Doventas Y. Effects of different levels of end-expiratory pressure on hemodynamic, respiratory mechanics and systemic stress response during laparoscopic cholecystectomy. Rev Bras Anestesiol 2017; 67: 28-34.

18. Valenza F, Vagginelli F, Tiby A, Francesconi S, Ronzoni G, Guglielmi M, et al. Effects of the beach chair position, positive end-expiratory pressure, and pneumoperitoneum on respiratory function in morbidly obese patients during anesthesia and paralysis. Anesthesiology 2007; 107: 725-32.

19. Erlandsson K, Odenstedt H, Lundin S, Stenqvist O. Positive end-expiratory pressure optimization using electric impedance tomography in morbidly obese patients during laparoscopic gastric bypass surgery. Acta Anaesthesiol Scand 2006; 50: 833-9. 
20. Valente Barbas CS. Lung recruitment maneuvers in acute respiratory distress syndrome and facilitating resolution. Crit Care Med 2003; 31(4 Suppl): S265-71.

21. Schreiter D, Reske A, Stichert B, Seiwerts M, Bohm SH, Kloeppel R, et al. Alveolar recruitment in combination with sufficient positive endexpiratory pressure increases oxygenation and lung aeration in patients with severe chest trauma. Crit Care Med 2004; 32: 968-75.

22. Pelosi P, Gama de Abreu M, Rocco PR. New and conventional strategies for lung recruitment in acute respiratory distress syndrome. Crit Care 2010; 14: 210.

23. Pelosi P, Goldner M, McKibben A, Adams A, Eccher G, Caironi P, et al. Recruitment and derecruitment during acute respiratory failure: an experimental study. Am J Respir Crit Care Med 2001; 164: 122-30.

24. Park HP, Hwang JW, Kim YB, Jeon YT, Park SH, Yun MJ, et al. Effect of pre-emptive alveolar recruitment strategy before pneumoperitoneum on arterial oxygenation during laparoscopic hysterectomy. Anaesth Intensive Care 2009; 37: 593-7.

25. Futier E, Constantin JM, Pelosi P, Chanques G, Kwiatkoskwi F, Jaber S, et al. Intraoperative recruitment maneuver reverses detrimental pneumoperitoneum-induced respiratory effects in healthy weight and obese patients undergoing laparoscopy. Anesthesiology 2010; 113: 1310-9.

26. Reinius H, Jonsson L, Gustafsson S, Sundbom M, Duvernoy O, Pelosi P, et al. Prevention of atelectasis in morbidly obese patients during general anesthesia and paralysis: a computerized tomography study. Anesthesiology 2009; 111: 979-87.

27. Ahn S, Byun SH, Chang H, Koo YB, Kim JC. Effect of recruitment maneuver on arterial oxygenation in patients undergoing robot-assisted laparoscopic prostatectomy with intraoperative $15 \mathrm{cmH}_{2} \mathrm{O}$ positive end expiratory pressure. Korean J Anesthesiol 2016; 69: 592-8.

28. Whalen FX, Gajic O, Thompson GB, Kendrick ML, Que FL, Williams BA, et al. The effects of the alveolar recruitment maneuver and positive end-expiratory pressure on arterial oxygenation during laparoscopic bariatric surgery. Anesth Analg 2006; 102: 298-305.

29. Huang CC, Shih MJ, Tsai YH, Chang YC, Tsao TC, Hsu KH. Effects of inverse ratio ventilation versus positive end-expiratory pressure on gas exchange and gastric intramucosal $\mathrm{PCO}_{2}$ and $\mathrm{pH}$ under constant mean airway pressure in acute respiratory distress syndrome. Anesthesiology 2001; 95: 1182-8.

30. Marcy TW, Marini JJ. Inverse ratio ventilation in ARDS. Rationale and implementation. Chest 1991; 100: 494-504.

31. Lessard MR, Guérot E, Lorino H, Lemaire F, Brochard L. Effects of pressure-controlled with different I:E ratios versus volume-controlled ventilation on respiratory mechanics, gas exchange, and hemodynamics in patients with adult respiratory distress syndrome. Anesthesiology 1994; 80: 983-91.

32. Gurevitch MJ, Van Dyke J, Young ES, Jackson K. Improved oxygenation and lower peak airway pressure in severe adult respiratory distress syndrome. Treatment with inverse ratio ventilation. Chest 1986; 89: 211-3.

33. Jo YY, Kim JY, Chang YJ, Lee S, Kwak HJ. The effect of equal ratio ventilation on oxygenation, respiratory mechanics, and cerebral perfusion pressure during laparoscopy in the trendelenburg position. Surg Laparosc Endosc Percutan Tech 2016; 26: 221-5.

34. Park JH, Lee JS, Lee JH, Shin S, Min NH, Kim MS. Effect of the prolonged inspiratory to expiratory ratio on oxygenation and respiratory mechanics during surgical procedures. Medicine (Baltimore) 2016; 95: e3269.

35. Kim WH, Hahm TS, Kim JA, Sim WS, Choi DH, Lee EK, et al. Prolonged inspiratory time produces better gas exchange in patients undergoing laparoscopic surgery: a randomised trial. Acta Anaesthesiol Scand 2013; 57: 613-22.

36. Jo YY, Kim JY, Park CK, Chang YJ, Kwak HJ. The effect of ventilation strategy on arterial and cerebral oxygenation during laparoscopic bariatric surgery. Obes Surg 2016; 26: 339-44.

37. Lee K, Oh YJ, Choi YS, Kim SH. Effects of a 1:1 inspiratory to expiratory ratio on respiratory mechanics and oxygenation during one-lung ventilation in patients with low diffusion capacity of lung for carbon monoxide: a crossover study. J Clin Anesth 2015; 27: 445-50.

38. Kim MH, Lee KY, Lee KY, Min BS, Yoo YC. Maintaining optimal surgical conditions with low insufflation pressures is possible with deep neuromuscular blockade during laparoscopic colorectal surgery: a prospective, randomized, double-blind, parallel-group clinical trial. Medicine (Baltimore) 2016; 95: e2920.

39. Kopman AF, Naguib M. Laparoscopic surgery and muscle relaxants: is deep block helpful? Anesth Analg 2015; 120: 51-8.

40. Dubois PE, Putz L, Jamart J, Marotta ML, Gourdin M, Donnez O. Deep neuromuscular block improves surgical conditions during laparoscopic hysterectomy: a randomised controlled trial. Eur J Anaesthesiol 2014; 31: 430-6.

41. Carron M. Respiratory benefits of deep neuromuscular block during laparoscopic surgery in a patient with end-stage lung disease. Br J Anaesth 2015; 114: 158-9. 